\title{
Delineation of Borrelia burgdorferi sensu lato species by multilocus sequence analysis and confirmation of the delineation of Borrelia spielmanii sp. nov.
}

\author{
Dania Richter, ${ }^{1}$ Danièle Postic, ${ }^{2}$ Natacha Sertour, ${ }^{2}$ lan Livey, ${ }^{3}$ \\ Franz-Rainer Matuschka ${ }^{1}$ and Guy Baranton ${ }^{2}$ \\ ${ }^{1}$ Charité Universitätsmedizin Berlin, 12249 Berlin, Germany \\ ${ }^{2}$ Institut Pasteur, 75724 Paris, France \\ ${ }^{3}$ Baxter Vaccine AG, A-2304 Orth/Donau, Austria
}

\begin{abstract}
To evaluate multilocus sequence analysis (MLSA) for taxonomic purposes in the delineation of species within Borrelia burgdorferi sensu lato, seven relevant loci of various strains for which extensive DNA-DNA reassociation data were available were sequenced. MLSA delineation proved to be fully concordant with conventional methods. Our analysis confirmed the delineation of a novel species, Borrelia spielmanii sp. nov., previously known as 'Borrelia spielmani' Richter et al. 2004, with strain PC-Eq17N5 ${ }^{\top}\left(=\mathrm{DSM} 16813^{\top}=\mathrm{CIP} 108855^{\top}\right)$ as the type strain.
\end{abstract}

\section{INTRODUCTION}

Borrelia burgdorferi sensu lato (B. burgdorferi s.l.) is a complex of at least 12 species, of which Borrelia burgdorferi sensu stricto (s.s.) (Johnson et al., 1984), Borrelia garinii (Baranton et al., 1992) and Borrelia afzelii (Canica et al., 1993) cause Lyme disease in humans. Particular species, such as Borrelia japonica (Kawabata et al., 1993), 'Borrelia andersonii' (Marconi et al., 1995), 'Borrelia bissettii' (Postic et al., 1998), Borrelia sinica (Masuzawa et al., 2001), Borrelia turdi and Borrelia tanukii (Fukunaga et al., 1996), appear not to be pathogenic and have a restricted geographical distribution. Borrelia valaisiana (Wang et al., 1997), which is widely distributed in Europe and Asia, and Borrelia lusitaniae (Le Fleche et al., 1997), which infects vector ticks in Europe and North Africa (Younsi et al., 2005), are potentially pathogenic. DNA specific for B. valaisiana has been detected

Published online ahead of print on 9 December 2005 as DOI 10.1099/ ijs.0.64050-0.

Abbreviations: MLEE, multilocus enzyme electrophoresis; MLSA, multilocus sequence analysis; MLST, multilocus sequence typing; WDDH, whole DNA-DNA hybridization.

The GenBank/EMBL/DDBJ accession numbers for the fla, groEL, $h b b$, ospA, recA, rrs and rrf-rrl intergenic spacer gene sequences of Borrelia spielmanii sp. nov. PC-Eq17N5 ${ }^{\top}$ are DQ133508, DQ133511, DQ133514, DQ133517, DQ133520, DQ133523 and DQ133526, respectively. Accession numbers for other gene sequences obtained in this study are given in Supplementary Table S2 in IJSEM Online.

Tables detailing similarity values for concatenated sequences of species within Borrelia burgdorferi s.l. and GenBank accession numbers for gene sequences derived in this study are available as supplementary material in IJSEM Online. in human samples (Rijpkema et al., 1997; Diza et al., 2004) and a strain of $B$. lusitaniae has been isolated from the skin of a patient (Collares-Pereira et al., 2004). The most recent species described within the complex of B. burgdorferi s.l. was previously effectively published as 'Borrelia spielmani' Richter et al. 2004. Its exceptionally narrow specificity for a particular reservoir host, garden and hazel dormice, distinguishes it from all other Lyme disease spirochaetes (Richter et al., 2004). This unique biological relationship, together with its genotypic and phenotypic characteristics (Van Dam et al., 1993; Wang et al., 1999; Derdáková et al., 2003; Richter et al., 2004), suggested that this dormouse-associated spirochaete constitutes a distinct novel species. However, because of the lack of DNA-DNA hybridization data, the name of this species has not been validly published. Current practice requires that validation of a novel bacterial species should be based on the level of DNA-DNA reassociation by means of whole DNA-DNA hybridization (WDDH), which is considered to be the gold standard in taxonomy (Wayne et al., 1987). Few laboratories, however, can perform this technique, because it is non-cumulative and must include reference strains for all known species. Moreover, this method is not applicable for bacteria that cannot be cultivated and its application for slow-growing bacteria is limited. In addition, WDDH data may not be reproducible (Stackebrandt et al., 2002). Thus, alternative methods that can replace DNADNA reassociation are required (Stackebrandt et al., 2002).

The rapid development of sequencing techniques has made their application inexpensive and permits structural analysis of bacterial populations (Achtman, 2004). Multilocus sequence typing (MLST) is based on the identification of 
allelic mismatches of usually seven housekeeping genes (Selander et al., 1986; Gevers et al., 2005). It has been used to reveal the population structure of diverse prokaryotic organisms at the intraspecific level, including B. burgdorferi s.s. and B. afzelii (Bunikis et al., 2004; Qiu et al., 2004). Recently, it was proposed that multilocus sequence analysis (MLSA), a phylogenetic characterization using sequences of alleles of several genes, should be applied for species delineation (Gevers et al., 2005). For MLSA, sequences are processed using a distance method procedure rather than the cluster analysis procedure used in MLST. This tool may replace DNA-DNA reassociation, provided that both techniques demonstrate a sufficient degree of congruence (Stackebrandt et al., 2002). We have previously accumulated values for DNA-DNA reassociation of all type strains and various other strains of B. burgdorferi s.l. by using the S1-TCA method (Grimont et al., 1980).

To validate the MLSA method for species delineation, we sequenced seven loci of numerous B. burgdorferi s.l. strains, including type strains, and compared the results with our extensive data collection of DNA-DNA similarity and thermal stability. MLSA was subsequently applied to several isolates of the recently described, but not yet validly published, species 'B. spielmani' Richter et al. 2004.

\section{METHODS}

B. burgdorferi s.l. strains. The strains used in this study (Table 1) belong to five species endemic to Europe, B. burgdorferi s.s., B. garinii, $B$. afzelii, B. valaisiana and $B$. lusitaniae. Information regarding DNA-DNA reassociation was available for each of these strains
(Postic et al., 1990; Baranton et al., 1992; Canica et al., 1993; Le Fleche et al., 1997; Wang et al., 1997) and sequences at several of the selected loci were accessible from the literature or databases (Postic et al., 1994; Le Fleche et al., 1997; Valsangiacomo et al., 1997; Wang et al., 1997; Casati et al., 2004; Park et al., 2004). For the delineation of 'B. spielmani' by MLSA, we used the first isolate described of this group, strain A14S, which was isolated from the erythema migrans of a patient, and three strains, including the type strain PC-Eq17N5 ${ }^{\mathrm{T}}$, derived from Ixodes ricinus ticks that had fed on each of three garden dormice (Eliomys quercinus), which had been livetrapped in Alsace, France (Richter et al., 2004), as well as two isolates obtained from acute skin lesions of a Danish and a Hungarian patient. DNA of each of these strains was extracted from the centrifugation pellet of cultivated isolates, either by boiling at $100{ }^{\circ} \mathrm{C}$ for 10 min or by using a QIAamp DNA mini kit (Qiagen).

MLSA. Seven loci, $r r s, h b b, g r o E L, r e c A$, fla, ospA and $r r f-r r l$ intergenic spacer, were selected for analysis (Table 2). All loci were amplified by a single PCR. The reactions were performed in a final volume of $50 \mu \mathrm{l}$, comprising $0 \cdot 2 \mu \mathrm{M}$ of each primer of a primer pair, $200 \mu \mathrm{M}$ of each dNTP, $1 \cdot 25$ or $1 \mathrm{U}$ Taq polymerase (QBiogene or Qiagen, respectively) and $1 \times$ Taq buffer $\left(1.5 \mathrm{mM} \mathrm{MgCl}_{2}\right)$. The mixture was placed in a thermocycler, heated to $93^{\circ} \mathrm{C}$ for $1 \mathrm{~min}$ and subjected to 35 cycles of denaturation for $1 \mathrm{~min}$ at $93{ }^{\circ} \mathrm{C}$, annealing for $1 \mathrm{~min}$ at either $51^{\circ} \mathrm{C}$ for $r r s$ and groEL loci or $59^{\circ} \mathrm{C}$ for the remaining loci and extension for $1 \mathrm{~min}$ at $72{ }^{\circ} \mathrm{C}$, followed by a final extension step at $72{ }^{\circ} \mathrm{C}$ for $5 \mathrm{~min}$. The products were sequenced either by Genome Express (Meylan, France) or by using the dideoxynucleotide chain-termination method on a Licor DNA4200 sequencer with the same primers as for PCR.

Sequence analysis. The CLUSTAL_X (Thompson et al., 1997) algorithm was used for sequence alignments and MEGA 3 (Kumar et al., 1993) software for phylogenetic analyses of both individual and concatenated sequences. Distances were calculated by using the Jukes and Cantor correction (Saitou \& Nei, 1987) in a pairwise deletion procedure. A similarity table was generated from a distance matrix

Table 1. Characteristics of the B. burgdorferi s.l. isolates used in MLSA

\begin{tabular}{|c|c|c|c|c|}
\hline Isolate & Species & Geographical origin & Biological origin & Reference \\
\hline IP1 & B. burgdorferi s.s. & France & Human $\mathrm{CSF}^{*}$ & Boerlin et al. (1992) \\
\hline VS461 $1^{\mathrm{T}}$ & B. afzelii & Switzerland & I. ricinus & Boerlin et al. (1992) \\
\hline PGau & B. afzelii & Germany & Human skin & Wilske et al. (1988) \\
\hline $\mathrm{BO} 23$ & B. afzelii & Sweden & Human skin & Postic et al. (1994) \\
\hline $\mathrm{PBi}$ & B. garinii & Germany & Human CSF & Preac-Mursic et al. (1986) \\
\hline NT29 & B. garinii & Japan & Ixodes persulcatus & Postic et al. (1994) \\
\hline VS116 ${ }^{\mathrm{T}}$ & B. valaisiana & Switzerland & I. ricinus & Wang et al. (1997) \\
\hline UK & B. valaisiana & UK & I. ricinus & Wang et al. (1997) \\
\hline PotiB2 ${ }^{\mathrm{T}}$ & B. lusitaniae & Portugal & I. ricinus & Le Fleche et al. (1997) \\
\hline A14S & B. spielmanii & The Netherlands & Human skin & Wang et al. (1999) \\
\hline DK35 & B. spielmanii & Denmark & Human skin & Theisen et al. (1995) \\
\hline PZ30802 & B. spielmanii & Hungary & Human skin & This study \\
\hline
\end{tabular}

${ }^{\star}$ CSF, Cerebrospinal fluid. 
Table 2. Characteristics of amplified fragments and corresponding primer sequences

Numbering derives from B. burgdorferi s.s. strain $\mathrm{B} 31^{\mathrm{T}}$. F, Forward; R, reverse. $\mathrm{W}=\mathrm{A}$ or $\mathrm{T}$.

\begin{tabular}{|c|c|c|c|}
\hline Locus & Fragment length (bp) & Primers & Sequence analysed \\
\hline \multirow[t]{2}{*}{ rrs } & 522 & F: AGAGTTTGATCCTGGCTTAG (10-29) & $30-551$ \\
\hline & & R: CTTTACGCCCAATAATCCCGA (572-552) & \\
\hline fla & & R: GATTWGCRTGCGCAATCATTGCC (976-954) & \\
\hline groEL & 268 & F: TACGATTTCTTATGTTGAGGG (552-572) & $573-840$ \\
\hline$h b b$ & & R: TATAAGAATTCACGATATTAACTGGC (End to +26) & \\
\hline \multirow[t]{2}{*}{ recA } & 156 & F: GTGGATCTATTGTATTAGATGAAGCTCTTG (170-199) & $206-361$ \\
\hline & & R: GCCAAAGTTCTGAAACATTAACTCCCAAAG (391-362) & \\
\hline \multirow[t]{2}{*}{ ospA } & 261 & F: AATAGGTCTAATATTAGCCTTAATAGC (21-47) & $48-308$ \\
\hline & & R: TTGATACTAATGTTTTGCCATCTTCTT (334-308) & \\
\hline
\end{tabular}

( $P$ distance values) with Excel. Unweighted pair group with mathematical average (UPGMA) (Sneath \& Sokal, 1962) and neighbourjoining (NJ) (Saitou \& Nei, 1987) methods were both used to construct phylogenetic trees. Percentage support values were obtained using a bootstrap procedure.

\section{RESULTS}

\section{MLSA of strains representative of $B$. burgdorferi s.I. species with validly published names}

To evaluate whether the seven loci, rrs, hbb, groEL, recA, fla, ospA and $r r f-r r l$ intergenic spacer, were appropriate for subsequent MLSA, we either sequenced them or obtained published sequences from databases for each of 13 selected isolates representing B. burgdorferi s.s., B. garinii, B. afzelii, $B$. valaisiana and B. lusitaniae and analysed their phylogenetic clustering. We generated a distance matrix from sequence alignments and constructed a phylogenetic tree for each locus. Independent of the method used for the phylogenetic analysis, such as UPGMA (Fig. 1) or NJ (data not shown), sequences from isolates belonging to each species with a validly published name constituted a single cluster on each individual tree. The $r r f-r r l$ intergenic spacer provided greater strain diversity within a species than did other loci. B. lusitaniae strains PotiB1 and $\mathrm{PotiB}^{\mathrm{T}}$ were particularly divergent at this locus, although their $r r f-r r l$ sequences were clearly distinct from those of other species. Otherwise, B. garinii clearly appears to be the most diverse species, because the strain clustering varied according to the locus targeted.

For subsequent MLSA, sequences of the seven loci were concatenated for each of the 13 representative B. burgdorferi s.l. strains, resulting in a total length of each concatenated sequence of $2100 \mathrm{bp}$, and analysed comparatively. The sequences clearly segregated according to the established delineation of B. burgdorferi s.l. species (Fig. 2), supported by bootstrap analysis. Similar results were obtained by using both UPGMA (Fig. 2a) and NJ (Fig. 2b) methods.

\section{Correlation between MLSA and DNA-DNA reassociation}

Genetic distances of concatenated sequences (Supplementary Table S1 in IJSEM Online, expressed as a similarity table), generated in MEGA software, were compared with those derived previously using WDDH (Postic et al., 1990, 1994; Baranton et al., 1992). The clustering of strains obtained by MLSA strongly associated with the clustering inferred from DNA-DNA relatedness values (Fig. 3). Within a species, defined by values of DNA-DNA relatedness above $70 \%$ and a thermal stability estimated at $\Delta T_{\mathrm{m}}$ below $5{ }^{\circ} \mathrm{C}$ (Wayne et al., 1987), sequence similarity values deduced from genetic distances ranged from $97 \cdot 9$ to $99 \cdot 8 \%$ (Supplementary Table S1 in IJSEM Online). In contrast, sequence similarity values compared across species ranged from 92 to $94.9 \%$ (Supplementary Table S1 in IJSEM Online). A slight interspecific discrepancy was observed when strains $B$. afzelii VS461 $1^{\mathrm{T}}$ and $B$. garinii PBi were compared. Although the similarity value was $94 \%$, the DNA-DNA relatedness reached $74 \%$. However, a $\Delta T_{\mathrm{m}}$ value of $9^{\circ} \mathrm{C}$ demonstrated that these strains comprised two distinct species, as did the MLSA similarity value determined in this study. An MLSA similarity value of $97.9 \%$, therefore, appears to be useful as a cut-off to differentiate B. burgdorferi s.l. species.

\section{Characterization of 'B. spielmani' using MLSA}

Sequences of strains of ' $B$. spielmani' clustered separately from those of all previously described B. burgdorferi s.l. species, independent of the locus targeted (Fig. 1). As for all other delineated species, the $r r f-r r l$ locus varied most. Sequences were scattered among three branches when published $r r f-r r l$ sequences of ' $B$. spielmani' isolates derived from either ticks [GenBank accession nos AY147009 

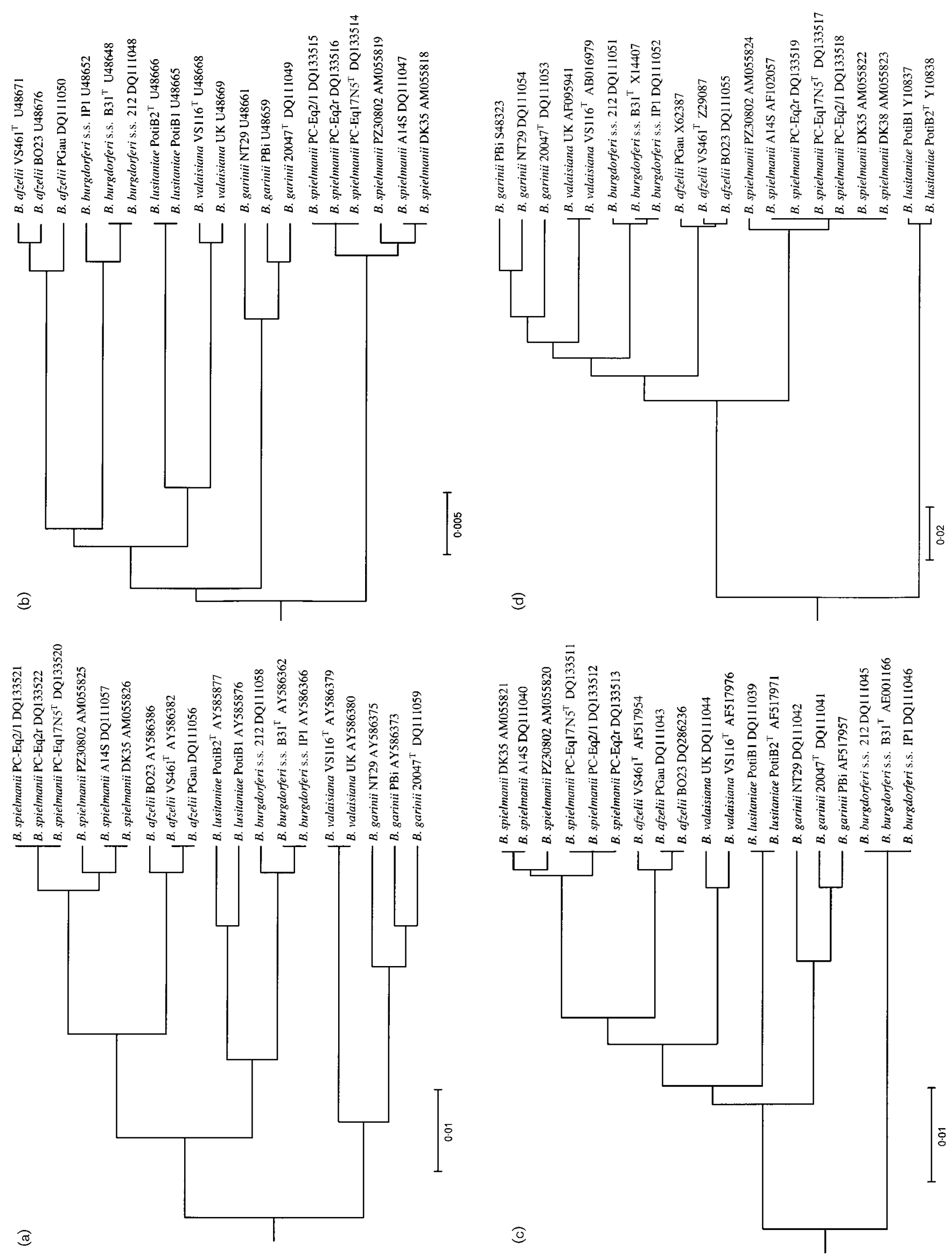
B. Iusitaniae PotiB I DQ11 1035

B. valaisiana UK DQ1 11038

$\left.\right|_{\text {B. valaisiana } \mathrm{VS} 116^{\mathrm{T}} \mathrm{DQ} 111037} ^{\text {B. valaisiana }}$

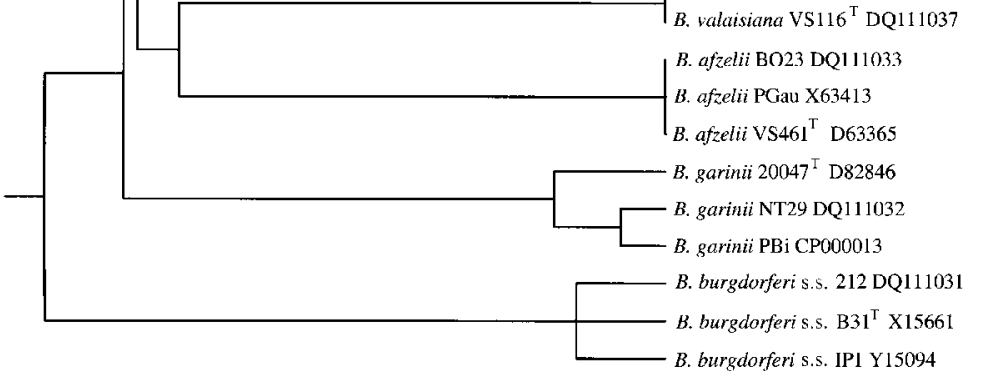

0.01

IPI Y15094

B. spielmanii 2102 DQ286234

(g) B. spielmanii PZ30802 AM055829

B. spielmanii 4AЛ $150 \mathrm{DQ} 286235$

B. spielmanii Ir-5215 AY573193

B. spielmanii I-77 AF497994

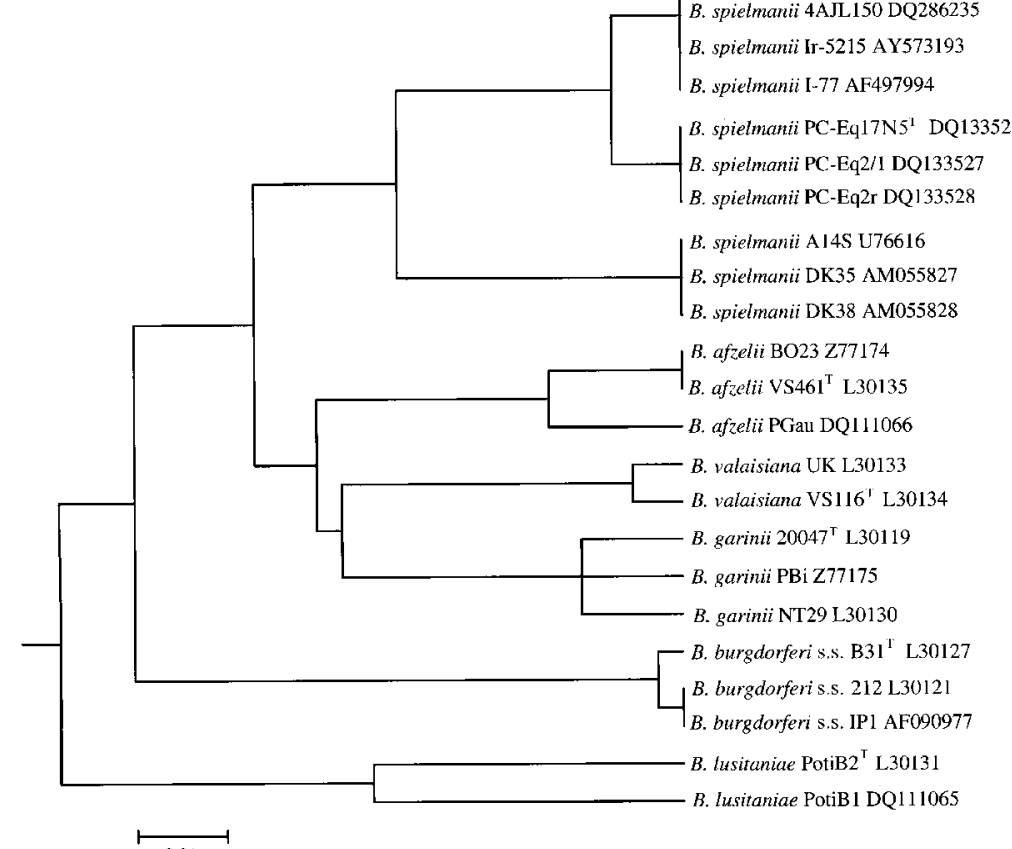

Fig. 1. Phylogenetic analysis of Borrelia burgdorferi s.l. based on individual sequences of seven loci, $\operatorname{rec} A(\mathrm{a}), h b b$ (b), groEL (c), $\operatorname{osp} A(\mathrm{~d})$, fla (e), rrs (f) and $r r f-r r l$ intergenic spacer (g), available from GenBank/EMBL/DDBJ databases or obtained in this study. Trees were constructed after multiple alignment of data using CLUSTAL_X (Thompson et al., 1997). Distances and clustering with UPGMA (Sneath \& Sokal, 1962) were performed using MEGA 3 (Kumar et al., 1993). Distances were calculated by using the Jukes and Cantor correction (Saitou \& Nei, 1987) in a complete deletion procedure. Bars, $1 \%$ difference in nucleotide sequence. 
(PC-Eq17N5 $^{\mathrm{T}}$ ), AY573193 and AF497994] or human samples (accession no. U76616) and unpublished sequences of isolates obtained in our laboratories from I. ricinus (PC-Eq2/1, PC-Eq2r and 4AJL150) or human skin (2102, PZ30802, DK35 and DK38) were included in the analysis. In contrast, the sequences of ' $B$. spielmani' were identical for the conserved fla locus and, more unexpectedly, were virtually identical for the ospA locus. A very similar clustering resulted from the phylogenetic analysis of the groEL, $h b b$ and recA loci.
When concatenated sequences were analysed, isolates of 'B. spielmani' appeared to be closely related to one another, but unambiguously diverged from all other species that were included in this study (Fig. 2). When we applied the MLSA similarity cut-off of $97.9 \%$ to 'B. spielmani', all examined isolates constituted a single and homogeneous species, with similarities ranging from $99 \cdot 2$ to $100 \%$, while differing from other species by similarity values of $92 \cdot 1-94 \cdot 8 \%$ (Supplementary Table S1 in IJSEM Online). (a)

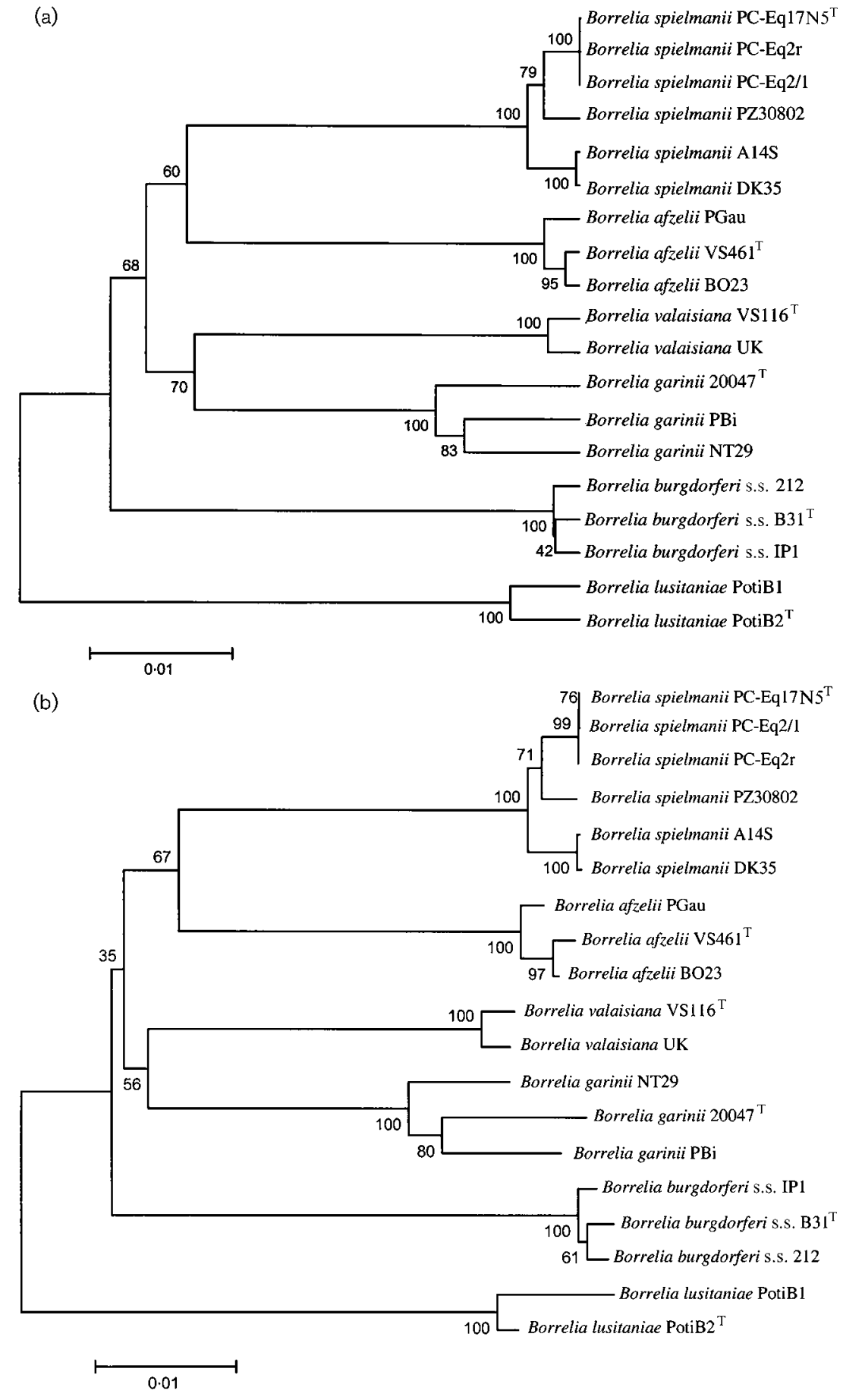

Fig. 2. Phylogenetic analysis of Borrelia burgdorferi s.l. based on concatenated sequences of seven loci, rrs, hbb, groEL, recA, fla, ospA and $r r f-r r l$ intergenic spacer, available from GenBank/EMBL/DDBJ databases or obtained in this study. Trees were constructed after multiple alignment of data using CLUSTAL_X (Thompson et al., 1997). Distances and clustering with UPGMA (Sneath \& Sokal, 1962) (a) or by using the NJ method (Saitou \& Nei, 1987) (b) were performed using MEGA 3 (Kumar et al., 1993). Distances were calculated as described for Fig. 1. Percentage support values were obtained using a bootstrap procedure based on 500 replications. Bars, 1\% difference in nucleotide sequence. 


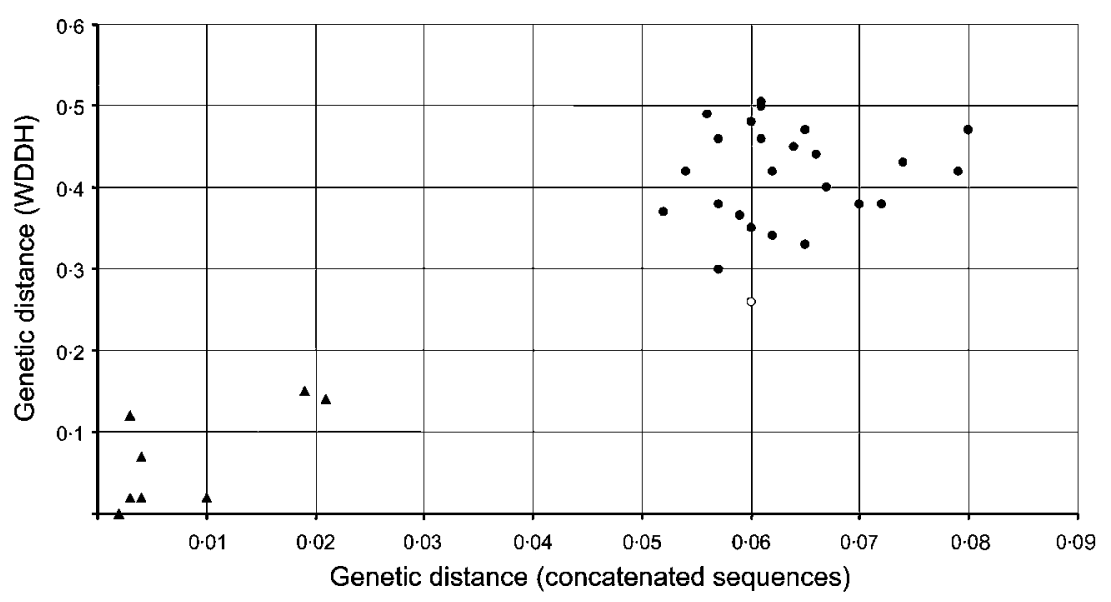

Fig. 3. Correlation of genetic distances determined by WDDH and by MLSA of concatenated sequences (see Supplementary Table S1 in IJSEM Online). Levels of DNA relatedness, derived from previous studies (Postic et al., 1990, 1994; Baranton et al., 1992; D. Postic, unpublished data), were converted to genetic distances. Values for genetic distances obtained by either of the two methods correlated within ( $(\boldsymbol{A})$ and between $(\boldsymbol{O})$ species. Values smaller than a genetic distance of 0.3 determined by WDDH generally designate an intraspecific relationship (Wayne et al., 1987). The WDDH value of 0.26 determined for strains $B$. afzelii $\mathrm{VS} 461^{\top}$ and $B$. garinii $\mathrm{PBi}(\bigcirc)$ constitutes an exception.

\section{DISCUSSION}

Phylogenetic analysis of a single locus generally serves to evaluate the genetic diversity within a species. Ribosomal genes and spacers, however, have been used for species delineation (Marconi et al., 1995). Moreover, several methodologies showed a good correlation with WDDH data. For example, analysis of B. burgdorferi s.l. strains by multilocus enzyme electrophoresis (MLEE; Boerlin et al., 1992) produced values that strongly correlated to those of DNA-DNA reassociation (Baranton et al., 1992). Even arbitrarily primed PCR (Welsh et al., 1992) suggested that isolate DN127 differed from other previously studied isolates and may be a member of a novel species. Indeed, subsequently, isolate $\mathrm{DN} 127$ was proposed as the type strain of 'B. bissettii' (Postic et al., 1998). However, methods involving multiple loci distributed on the whole genome of an organism provide a more valuable alternative to laborious DNA-DNA reassociation (Stackebrandt et al., 2002). MLST and recently, more appropriately, MLSA, have been proposed as true alternatives to DNA-DNA reassociation for taxonomic purposes (Lan \& Reeves, 2001; Stackebrandt et al., 2002; Gevers et al., 2005). Well-defined conditions for MLST have to be met, in particular the requirement for a minimum of five housekeeping genes under stabilizing selection, in order to obtain an informative level of data (Stackebrandt et al., 2002). Whereas MLST characterizes genotypic relationships of prokaryotes at an intraspecific level by identifying allelic mismatches of housekeeping genes, MLSA permits phylogenetic characterization by yielding clusters of concatenated sequences of multiple genes (Gevers et al., 2005). In our MLSA study, we used seven loci whose relevance for taxonomic studies of $B$. burgdorferi s.l. had been demonstrated previously. Five of them are located on the chromosome and therefore evolved in a clonal way, while not being subjected to lateral transfer (Dykhuizen et al., 1993): rrs gene (Le Fleche et al., 1997; Wang et al., 1997; Postic et al., 1998), fla gene (Fukunaga \& Koreki, 1996), groEL gene (Park et al., 2004), hbb gene
(Valsangiacomo et al., 1997) and recA gene (Casati et al., 2004). Instead of operational genes, we chose informational genes ( $r r s, h b b, g r o E L, r e c A)$ that are embedded in a network of interactions and are subjected only minimally to lateral transfer (Jain et al., 1999). We added the fla gene, encoding flagellin, because it constitutes the endoflagella of spirochaetes and therefore is not targeted by selective pressure of the host's immune response. The ospA locus, on the other hand, represents an adaptive, plasmid-encoded gene, which has been employed previously for taxonomic purposes (Dykhuizen et al., 1993; Bunikis et al., 2004). Although this gene may be subject to lateral transfer, it occurs only rarely (Dykhuizen et al., 1993). In fact, the tree generated from the ospA gene appeared to evolve clonally for all sequences studied. Finally, we chose the non-coding locus rrf-rrl intergenic spacer, as its sequence correlates well taxonomically (Postic et al., 1994). These last two loci represent the fast-evolving part of the genome, contrasting with the other loci. Independent of the locus considered, the phylogeny reflects taxonomic associations, thereby confirming that B. burgdorferi s.l. evolves clonally (Dykhuizen et al., 1993).

MLST was originally designed for epidemiological purposes (Achtman, 2004). The related, but phylogenetic, approach, which was recently termed MLSA (Gevers et al., 2005), has been used successfully to delineate species of highly recombinogenic bacteria (Hanage et al., 2005). We demonstrate here for B. burgdorferi s.l. that sequence similarities derived by MLSA strictly correlate with data inferred from WDDH. Relatedness deduced from MLSA, therefore, is applicable for distinguishing $B$. burgdorferi s.l. species, if performed with a sufficient number of appropriately selected loci. Species delineation by MLSA must be based on a cut-off in sequence similarity that is determined by comparing genetic distances obtained from both DNA-DNA reassociation and MLSA. As the similarity cut-off, we selected the widest genetic distance corresponding to the lowest percentage similarity recorded within any of the previously recognized B. burgdorferi s.l. species. Phylogenetic analyses of concatenated 
sequences in a bootstrap procedure provided additional support of the robustness of MLSA. Therefore, MLSA constitutes a valuable alternative to laborious DNA-DNA hybridization.

Using MLSA, we confirmed the status of a previously delineated species among the B. burgdorferi s.l. complex, ' $B$. spielmani'. This species is characterized by a peculiar reservoir relationship. In nature, strains of ' $B$. spielmani' perpetuate in garden and hazel dormice (Richter et al., 2004). No other member of the B. burgdorferi s.l. complex is restricted to such a narrow host range. This unique ecological niche together with its genotypic and phenotypic characteristics (Van Dam et al., 1993; Wang et al., 1998; Derdáková et al., 2003; Richter et al., 2004) distinguish it from all other spirochaetes causing Lyme disease. The distinctiveness of ' $B$. spielmani' is fully reflected in our MLSA analysis.

Numerous questing I. ricinus ticks and those feeding on dormice have been found to harbour strains of 'B. spielmani' in France (Richter et al., 2004). Questing ticks infected by this dormouse-associated spirochaete have also been collected in the Czech Republic (Derdáková et al., 2003), Russia (GenBank accession no. AY573193) and Germany (Rauter et al., 2002). 'B. spielmani causes erythema migrans in humans and was isolated from or detected in patients' skin in the Netherlands (Van Dam et al., 1993), Slovenia (E. RuzicSabljic, unpublished data), Hungary (Földvári et al., 2005), twice in Denmark (I. Livey, unpublished data) and twice in Germany (Michel et al., 2004). Hitherto, 'B. spielmani' has been detected in ticks and patients solely in Europe; its distribution may correspond closely to that of dormice.

\section{Description of Borrelia spielmanii sp. nov.}

Borrelia spielmanii (spi.el.man'i.i. N.L. gen. n. spielmanii of Spielman, named in honour of Andrew Spielman, who described for the first time the life cycle and biological relationships of B. burgdorferi s.l.).

Previously effectively published as 'Borrelia spielmani' Richter et al. 2004. The description is given in Richter et al. (2004). Note that the spelling of the name B. spielmanii has been corrected. The type strain is PC-Eq17N5 $5^{\mathrm{T}}(=\mathrm{DSM}$ $16813^{\mathrm{T}}=$ CIP $108855^{\mathrm{T}}$ ).

Taken together, the MLSA results agree fully with data obtained by WDDH. MLSA therefore constitutes a valuable alternative for a reliable and precise delineation of $B$. burgdorferi s.l. species. This methodology results in solid sequence data with a highly discriminatory power that are not subject to experimental variation and may easily be shared, allowing interlaboratory comparison. It is important that this technique is widely adopted, because it facilitates studies on various bacterial isolates that hitherto remain unclassified due to the impediment of cumbersome methods.

\section{ACKNOWLEDGEMENTS}

This study was supported by grants Ma 942/10-1 and -2 from the Deutsche Forschungsgemeinschaft (to F.-R.M.). We thank Mandy Pötter, Andrea Schäfer, Udo Bischoff, Martine Garnier and M.-L. Zips for excellent technical assistance.

\section{REFERENCES}

Achtman, M. (2004). Population structure of pathogenic bacteria revisited. Int J Med Microbiol 294, 67-73.

Baranton, G., Postic, D., Saint Girons, I., Boerlin, P., Piffaretti, J.-C., Assous, M. \& Grimont, P. A. D. (1992). Delineation of Borrelia burgdorferi sensu stricto, Borrelia garinii sp. nov., and group VS461 associated with Lyme borreliosis. Int J Syst Bacteriol 42, 378-383.

Boerlin, P., Peter, O., Bretz, A. G., Baranton, G. \& Piffaretti, J.-C. (1992). Population genetic analysis of Borrelia burgdorferi isolates by multilocus enzyme electrophoresis. Infect Immun 60, 1677-1683.

Bunikis, J., Garpmo, U., Tsao, J., Berglund, J., Fish, D. \& Barbour, A. G. (2004). Sequence typing reveals extensive strain diversity of the Lyme borreliosis agents Borrelia burgdorferi in North America and Borrelia afzelii in Europe. Microbiology 150, 1741-1755.

Canica, M. M., Nato, F., du Merle, L., Mazie, J. C., Baranton, G. \& Postic, D. (1993). Monoclonal antibodies for identification of Borrelia afzelii sp. nov. associated with late cutaneous manifestations of Lyme borreliosis. Scand J Infect Dis 25, 441-448.

Casati, S., Bernasconi, M. V., Gern, L. \& Piffaretti, J. C. (2004). Diversity within Borrelia burgdorferi sensu lato genospecies in Switzerland by recA gene sequence. FEMS Microbiol Lett 238, 115-123.

Collares-Pereira, M., Couceiro, S., Franca, I. \& 7 other authors (2004). First isolation of Borrelia lusitaniae from a human patient. J Clin Microbiol 42, 1316-1318.

Derdáková, M., Beati, L., Pet'ko, L., Stanko, M. \& Fish, D. (2003). Genetic variability within Borrelia burgdorferi sensu lato genospecies established by PCR-single strand conformation polymorphism analysis of the $r r f A-r r l B$ intergenic spacer in Ixodes ricinus ticks from the Czech Republic. Appl Environ Microbiol 69, 509-516.

Diza, E., Papa, A., Vezyri, E., Tsounis, S., Milonas, I. \& Antoniadis, A. (2004). Borrelia valaisiana in cerebrospinal fluid. Emerg Infect Dis 10, 1692-1693.

Dykhuizen, D. E., Polin, D. S., Dunn, J. J., Wilske, B., Preac-Mursic, V., Dattwyler, R. J. \& Luft, B. J. (1993). Borrelia burgdorferi is clonal: implications for taxonomy and vaccine development. Proc Natl Acad Sci U S A 90, 10163-10167.

Földvári, G., Farkas, R. \& Lakos, A. (2005). Borrelia spielmanii erythema migrans, Hungary. Emerg Infect Dis 11, 1794-1795.

Fukunaga, M. \& Koreki, Y. (1996). A phylogenetic analysis of Borrelia burgdorferi sensu lato isolates associated with Lyme disease in Japan by flagellin gene sequence determination. Int J Syst Bacteriol 46, 416-421.

Fukunaga, M., Hamase, A., Okada, K. \& Nakao, M. (1996). Borrelia tanukii sp. nov. and Borrelia turdae sp. nov. found from ixodid ticks in Japan: rapid species identification by 16S rRNA gene-targeted PCR analysis. Microbiol Immunol 40, 877-881.

Gevers, D., Cohan, F. M., Lawrence, J. G. \& 8 other authors (2005). Re-evaluating prokaryotic species. Nature Rev Microbiol 3, 733-739. Grimont, P. A. D., Popoff, M. Y., Grimont, F., Coynault, C. \& Lemelin, M. (1980). Reproducibility and correlation study of three deoxyribonucleic acid hybridization procedures. Curr Microbiol 4, 325-330.

Hanage, W. P., Fraser, C. \& Spratt, B. G. (2005). Fuzzy species among recombinogenic bacteria. BMC Biology 3, 6 . 
Jain, R., Rivera, M. C. \& Lake, J. A. (1999). Horizontal gene transfer among genomes: the complexity hypothesis. Proc Natl Acad Sci U S A 96, 3801-3806.

Johnson, R. C., Schmid, G. P., Hyde, F. W., Steigerwalt, A. G. \& Brenner, D. J. (1984). Borrelia burgdorferi sp. nov. etiologic agent of Lyme disease. Int J Syst Bacteriol 34, 496-497.

Kawabata, H., Masuzawa, T. \& Yanagihara, Y. (1993). Genomic analysis of Borrelia japonica sp. nov. isolated from Ixodes ovatus in Japan. Microbiol Immunol 37, 843-848.

Kumar, S., Tamura, K. \& Masatoshi, N. (1993). MEGA: molecular evolutionary genetics analysis, version 1.01. University Park, PA: The Pennsylvania State University.

Lan, R. \& Reeves, P. R. (2001). When does a clone deserve a name? A perspective on bacterial species based on population genetics. Trends Microbiol 9, 419-424.

Le Fleche, A., Postic, D., Girardet, K., Peter, O. \& Baranton, G. (1997). Characterization of Borrelia lusitaniae sp. nov. by $16 \mathrm{~S}$ ribosomal DNA sequence analysis. Int J Syst Bacteriol 47, 921-925.

Marconi, R. T., Liveris, D. \& Schwartz, I. (1995). Identification of novel insertion elements, restriction fragment length polymorphism patterns, and discontinuous $23 \mathrm{~S}$ rRNA in Lyme disease spirochetes: phylogenetic analyses of rRNA genes and their intergenic spacers in Borrelia japonica sp. nov. and genomic group 21038 (Borrelia andersonii sp. nov.) isolates. J Clin Microbiol 33, 2427-2434.

Masuzawa, T., Takada, N., Kudeken, M., Fukui, T., Yano, Y., Ishiguro, F., Kawamura, Y., Imai, Y. \& Ezaki, T. (2001). Borrelia sinica sp nov., a Lyme disease-related Borrelia species isolated in China. Int J Syst Evol Microbiol 51, 1817-1824.

Michel, H., Wilske, B., Hettche, G., Göttner, G., Heimerl, C., Reischl, U., Schulte-Spechtel, U. \& Fingerle, V. (2004). An ospA-polymerase chain reaction/restriction fragment length polymorphism-based method for sensitive detection and reliable differentiation of all European Borrelia burgdorferi sensu lato species and OspA types. Med Microbiol Immunol 193, 219-226.

Park, H. S., Lee, J. H., Jeong, E. J., Park, T. K., Jang, W. J., Park, K. H., Kim, B. J., Kook, Y. H. \& Lee, S. H. (2004). Evaluation of groEL gene analysis for identification of Borrelia burgdorferi sensu lato. J Clin Microbiol 42, 1270-1273.

Postic, D., Edlinger, C., Richaud, C., Grimont, F., Dufresne, Y., Perolat, P., Baranton, G. \& Grimont, P. A. (1990). Two genomic species in Borrelia burgdorferi. Res Microbiol 141, 465-475.

Postic, D., Assous, M. V., Grimont, P. A. D. \& Baranton, G. (1994). Diversity of Borrelia burgdorferi sensu lato evidenced by restriction fragment length polymorphism of $r r f(5 S)-r r l$ (23S) intergenic spacer amplicons. Int J Syst Bacteriol 44, 743-752.

Postic, D., Marti Ras, N., Lane, R. S., Hendson, M. \& Baranton, G. (1998). Expanded diversity among Californian Borrelia isolates and description of Borrelia bissettii sp. nov. (formerly Borrelia group DN127). J Clin Microbiol 36, 3497-3504.

Preac-Mursic, V., Wilske, B. \& Schierz, G. (1986). European Borrelia burgdorferi isolated from humans and ticks, culture conditions and antibiotic susceptibility. Zentralbl Bakteriol Mikrobiol Hyg 263, 112-118.

Qiu, W. G., Schutzer, S. E., Bruno, J. F., Attie, O., Xu, Y., Dunn, J. J., Fraser, C. M., Casjens, S. R. \& Luft, B. J. (2004). Genetic exchange and plasmid transfers in Borrelia burgdorferi sensu stricto revealed by three-way genome comparisons and multilocus sequence typing. Proc Natl Acad Sci U S A 101, 14150-14155.

Rauter, C., Oehme, R., Diterich, I., Engele, M. \& Hartung, T. (2002). Distribution of clinically relevant Borrelia genospecies in ticks assessed by a novel, single-run, real-time PCR. J Clin Microbiol 40, 36-43.

Richter, D., Schlee, D. B., Allgöwer, R. \& Matuschka, F.-R. (2004). Relationships of a novel Lyme disease spirochete, Borrelia spielmani sp. nov., with its hosts in Central Europe. Appl Environ Microbiol 70, 6414-6419.

Rijpkema, S. G., Tazelaar, D. J., Molkenboer, M. J., Noordhoek, G. T., Plantinga, G., Schouls, L. M. \& Schellekens, J. F. (1997). Detection of Borrelia afzelii, Borrelia burgdorferi sensu stricto, Borrelia garinii and group VS116 by PCR in skin biopsies of patients with erythema migrans and acrodermatitis chronica atrophicans. Clin Microbiol Infect 3, 109-116.

Saitou, N. \& Nei, M. (1987). The neighbor-joining method: a new method for reconstructing phylogenetic trees. Mol Biol Evol 4, 406-425.

Selander, R. K., Caugant, D. A., Ochman, H., Musser, J. M., Gilmour, M. N. \& Whittam, T. S. (1986). Methods of multilocus enzyme electrophoresis for bacterial population genetics and systematics. Appl Environ Microbiol 51, 873-884.

Sneath, P. H. A. \& Sokal, R. R. (1962). Numerical taxonomy. Nature 193, 855-860.

Stackebrandt, E., Frederiksen, W., Garrity, G. M. \& 10 other authors (2002). Report of the ad hoc committee for the re-evaluation of the species definition in bacteriology. Int J Syst Evol Microbiol 52, 1043-1047.

Theisen, M., Borre, M., Mathiesen, M. J., Mikkelsen, B., Lebech, A. M. \& Hansen, K. (1995). Evolution of the Borrelia burgdorferi outer surface protein OspC. J Bacteriol 177, 3036-3044.

Thompson, D., Gibson, T. J., Plewniak, F., Jeanmougin, F. \& Higgins, D. G. (1997). The CLUSTAL_X windows interface: flexible strategies for multiple sequence alignment aided by quality analysis tools. Nucleic Acids Res 25, 4876-4882.

Valsangiacomo, C., Balmelli, T. \& Piffaretti, J. C. (1997). A phylogenetic analysis of Borrelia burgdorferi sensu lato based on sequence information from the $h b b$ gene, coding for a histone-like protein. Int J Syst Bacteriol 47, 1-10.

Van Dam, A. P., Kuiper, H., Vos, K., Widjojokusumo, A., de Jongh, B. M., Spanjaard, L., Ramselaar, A. C. P., Kramer, M. D. \& Dankert, J. (1993). Different genospecies of Borrelia burgdorferi are associated with distinct clinical manifestations of Lyme borreliosis. Clin Infect Dis 17, 708-717.

Wang, G., van Dam, A. P., Le Fleche, A., Postic, D., Peter, O., Baranton, G., de Boer, R., Spanjaard, L. \& Dankert, J. (1997). Genetic and phenotypic analysis of Borrelia valaisiana sp. nov. (Borrelia genomic groups VS116 and M19). Int J Syst Bacteriol 47, 926-932.

Wang, G. Q., Van Dam, A. P., Spanjaard, L. \& Dankert, J. (1998). Molecular typing of Borrelia burgdorferi sensu lato by randomly amplified polymorphic DNA fingerprinting analysis. J Clin Microbiol 36, 768-776.

Wang, G. Q., van Dam, A. P. \& Dankert, J. (1999). Phenotypic and genetic characterization of a novel Borrelia burgdorferi sensu lato isolate from a patient with Lyme borreliosis. J Clin Microbiol 37, 3025-3028.

Wayne, L. G., Brenner, D. J., Colwell, R. R. \& 9 other authors (1987). Report of the ad hoc committee on reconciliation of approaches to bacterial systematics. Int J Syst Bacteriol 37, 463-464.

Welsh, J., Pretzman, C., Postic, D., Saint Girons, I., Baranton, G. \& McClelland, M. (1992). Genomic fingerprinting by arbitrarily primed polymerase chain reaction resolves Borrelia burgdorferi into three distinct phyletic groups. Int J Syst Bacteriol 42, 370-377.

Wilske, B., Preac-Mursic, V., Schierz, G., Kuhbeck, R., Barbour, A. G. \& Kramer, M. (1988). Antigenic variability of Borrelia burgdorferi. Ann N Y Acad Sci 539, 126-143.

Younsi, H., Sarih, M., Jouda, F., Godfroid, E., Gern, L., Bouattour, A., Baranton, G. \& Postic, D. (2005). Characterization of Borrelia lusitaniae isolates collected in Tunisia and Morocco. J Clin Microbiol 44, 1587-1593. 